position under the nipple, my conclusion is a certain affirm. ative."

Doubtless, in a case of suspected asthma, evidence of dilatation of the right side of the heart would strengthen the diagnosis; but the absence of it would go no way at all to negate the supposition that asthma existed. It would simply show that one of the results of asthma had not yet arisen, and it would establish a presumption that the disease had not been of long standing, that it was unassociated with chronic bronchitis, and that it had as yet inflicted no organic changes on the lungs. A patient's heart-beat may be in every way normal, and yet half an hour ago he may have been in the agonies of an asthmatic paroxysm. The positive evidence of heart-change in asthma is of some value; its negative evidence is worthless.

3. Emphysema is certainly the commonest of all the morbid changes that asthma tends to produce. I should say it was extremely rare to find the lungs of those who have suffered from asthma long entirely free from emphysematous inflation. The best examples of emphysema that I have ever seen have been in the post morten examinations of chronic asthma.

Adopting that view of emphysema so ably advocated by $\mathrm{Dr}$. Gairdner-that it is essentially a compensatory dilatation, and implies the neighbourhood of non-expansible lung-I believe the mechanism of the production of emphysema by asthma to be as follows:-The bronchial spasm shuts off the air; the shutting off the air produces capillary stasis-partial asphyxia; the congested vessels relieve themselves by the characteristic mucous exudation; the continued occlusion of the bronchial tubes, if the spasm does not yield, shuts up this mucus, and prevents its escape, and at the same time, by barring the access of air, prevents efficient cough; so long as the spasm lasts, therefore, its escape is doubly prevented-by direct obstruction, and by the want of the natural machinery for its expulsion. The tubes affected by the asthmatic contraction thus become doubly obstructed - at first narrowed by spasm, and then completely occluded by mucous infarction. As lons as the spasm lasts the escape of the mucus is impossible. In the meantime, whatever may have been the length of the attack (and we know that it often lasts for days), the in spiratory muscles are making the most violent efforts to fill the chest, and are, in fact, keeping it in a state of extreme distension.

The length of time required for the removal of air from a lobule, from which communication with the external atmosphere is completely shut off by occlusion of its corresponding bronchial tube, I do not know; so I do not know if, in an attack of asthma, any actual lobular collapse could take place, although, in a prolonged attack of some days I feel no doub that it would. At any rate, the lobules whose bronchiæ are occluded cannot yield to the distending force of the inspiratory muscles; the whole distension of inspiration is, therefore, spent on those portions of the lungs whose communication with the external air is free; the open lobules have to expand for themselves and their occluded neighbours, and undergo an excessive inflation in proportion to the amount of lung that is non-expansible,-in other words, become emphysematous. If we consider how complete the occlusion must be by this double process of spasm and infarction, how protracted asthma often is, and how violent are the inspiratory efforts that characterise it, I do not think we shall wonder at any amount of emphysema that is thereby produced, nor at its being one of the commonest organic changes to which asthma gives rise.

It will be seen, from the account I have just given, that asthma produces emphysema just in the same way that bronchitis does. The two processes are essentially identical. In the one case the bronchial tubes are narrowed by inflammatory thick. ening of their walls and occluded by inflammatory exudation (muco-pus); in the other, they are narrowed by spasmodic contraction and occluded by the exudation of congestion (viscid mucus). The only difference is, that the narrowing and occlusion of bronchitis are generally of longer duration than those of asthma.

I think Dr. Walshe is quite right in his opinion that " The connection of emphysema with spasmodic seizures is certainly sometimes, possibly always, dependent on an intervening irritative or passive congestion of the tubes." That it is so sometimes I think is certain, because I think that congestion of the tubes is the immediate result of prolonged spasm. But is it always? If not, then emphysema may result from the spastic occlusion of the tubes without any mucous infarction. Is this possible? Is asthmatic spasm ever so complete and continuous as to produce the results of plugging,--lobular isolation, and collapse? This is a question that I think would be very difficult, at present perhaps impossible, to answer. One thing I feel strongly persuaded of, that it is not necessary that there should be any bronchitic complication, anything actually inflammatory, in order that asthma should result in emphysema. I have seen emphysema developed in a case of asthma in which bronchitis never existed.

It is hardly worth while for me to describe the symptoms that mark the closing scene of those miserable cases of asthma that terminate in the production of these organic changes in the heart and lungs that $I$ have just been describing. When once the right cavities of the heart have become dilated and the obstructing force retrogrades upon the systemic veins, the symptoms are not to be distinguished from those which characterise a similar condition induced by chronic bronchitis. The cases differ alone in their previous history. There is the same rattling wheeze, the same choking cough, the same orthopnœa, the same abundant frothy expectoration (but in the case of bronchitis more purulent), the same venous regurgitation, the same choked-up breathlessness, getting ever worse and worse as the odema and congestive solidification rise higher and higher in the lungs, the same general œdema beginning at the feet and gradually creeping up the trunk, the same cyanosis. The sufferings of this gradual choking-out of life are most painful to witness till the increasing heaviness from the circulation of venous blood in the brain deepens into the insensibility which ushers in dissolution.

\section{OBSERVATIONS ON SOME OF THE OBSCURE FORMS AND VARIETIES OF AGUE: WITH GENERAL REMARKS ON THE DISEASE.}

By E. Garraway, Esq., Faversham.

[Real before the East Kent and Canterbury HIedical Society.]

THe phenomena of ague, so characteristic, so well known, and so often witnessed in this division of the county, might well be supposed to afford no difficulties in diagnosis; and when developed in its three consecutive stages of cold, fever, sweat, followed by immediate recovery, there can be none; but the variations which these phenomena assume, their sometimes absence, and their not unfrequent substitution by other symptoms, apparently totally unconnected with ague, and only known to be in alliance with it by their remission and return, render its discrimination a matter occasionally of no slight embarrassment.

You are sent for to a young man in previously good health, who is suddenly seized with great pain in the side, accompanied by severe vomiting, with or without acceleration of pulse, according to the time he may have been under the influence of the attack. You discard the idea of any inflammatory affection, and have little hesitation in pronouncing the case one of passing gall-stones. Nothing of the kind! Wait awhile, and your patient breaks out into a profuse sweat, and in a few hours is well; only, however, to have a repetition of the seizure on the next day or the day following.

A mother sends in terror for you to see her infant, perhaps only three or four weeks old. The child is cold ; its extremities are blue; pulse almost imperceptible; -in short, the little creature appears moribund. You think of imperfectly closed foramen ovale, of internal hæmorrhage, of accidental poisoning, -you do not know what to think, and communicate your fears to the anxious parent. Needless alarm! In due course the infant becomes warm again, then hot, and finally covered with beads of perspiration. This also was ague.

You are called to a child in convulsions, or to a supposed case of brain fever; perhaps, a young woman, whom you find delirious, with quick pulse, dry tongue, and burning skin. You are strongly tempted to leech, blister, and adopt antiphlogistic treatment; but, on inquiring, find that two days preceding the young woman or the child was similarly affected, though possibly in a lesser degree. This is all-sufficient for your diagnosis, you predict a resolution by sweat, and in a few hours your patient is recovering for that time.

The next case you find in bed, with a burning skin, rapid pulse, parched brown tongue, every limb racked with pain,-in short, all the symptoms of a low, continued fever. Such you pronounce it, and order aperients and salines. To your astonishment, on calling the following day, you find your patient eating his dinner, with a moist, clean tongue, cool skin, quiet pulse; in fine, convalescent. You rejoice with him on his speedy recovery. Vain exultation! To-morrow he is worse than ever; 
his tongue like brown toast; and did not the intermission enable you to call it ague, you might well be excused for pronouncing it a case of approaching typhus.

You are hastily summoned by the friends of an old gentleman to find him in a state bordering on coma. He is prostrate on the sofn, his eves half closed, his mouth open, his pulse feeble and intermitting. He appears neither to know nor understand you, as you ean elicit no answer to your questions. Reflecting upon his advanced age, you think of cerebral degeneration, of ramolissement or ossification ; communicate your alarm to his relatives, and think your octogenarian friend is at length going the way of all flesh. Not at all. "Doctor!"he exclaims the next day, with his bottle of port before him, "I've had a pretty good dose of your physic, now you must take a glass or two of mine." To-morrow, of course, the old gentleman is down again ; but you push quinine vigorously, and he is soon weil.

All who have any extensive experience of ague will readily admit that these are no exaggerated nor fancy pictures; but are really taken from the life; indeed, I have each individual case to which $I$ have alluded in my mind's eye at this moment.

But various and multiform as are the phases of intermittent fever or ague, still more are the protean manifestations of its kindrerl affection, neuralgia, which, in this neighbourhood at least, almost invariably assumes the intermittent form. It is needless to weary you with the attempt to enumerate the seats of this most painful-often excruciating-disorder. Let it sufince that wherever nerves of sensation are distributed there mav it fix its seat, simulating, like hysteria, a variety of intlammatory and other serious maladies, to which, however, it bears really no affinity whatever. It is worthy of note, too, that generally speaking no derangement of the prima via, no local nor constitutional cause can be traced as originating or keeping up the disorder, most of its subjects being, during the intervals of pain, in the enjoyment of perfect health. 'T'he cause must be sought for from without, that which originates ague in one constitution giving rise to neuralgia in another.

There is no question at all that marsh miasmata constitute the direct primary exciting cause of intermittent; and although it may be reinduced in a system already rendered prone to its invasion by exposure to cold and damp-the easterly wind, foul air, mental or physical depression, impoverished diet, etc- - yet these alone are not sufficient primarily to excite a paroxysm in one who may have been fortunate enough hitherto to have escaped its onslaught.

For the last year or two ague has been unusually rife in this locality; indeed, for universality and severity, $I$ have seen nothing like it since my first acquaintance with Faversham, now some twenty years ago. People of all ages and conditions have succumbel to it. I have been attending at the same moment patients from a fortnight old to eighty years. It has penetrated far and wide over the country, into districts where intermitten has scarcely ever before been known; and, taking into consideration the exceedingly dry character of the last two winters the public who think of ague in connection with wet and cold are sorely puzzled to account for its ravages. My medical brethren have, however, doubtless long since come to the same conclusion as myself, namely, that to these same exceedingly dry seasons may be attributed whatever extension of ague we may have had beyond its accustomed limits. During the year $185 \%$, meteorologists tell us that there was a deficiency of rain to the extent of six or eight inches, a very large amount; but they do not tell us that there was any material alteration in the hygrometric condition of the atmosphere. It appears to have contained its due proportion of moisture notwithstanding the earth's surface was for a considerable time preternaturally arid and dry. Whence then was this moisture derived? Obviously from such collections or natural supplies of water as might be nearest at hand; and in the case of Faversham, Sittingbourne, Milton, and the surrounding country, the supplies were necessarily drawn from the extensive tracts of marsh land in con nection with the river Medway and the Swale. Evaporation here went on to an enormous, probably an unprecedented, extent; and the prevailing winds carried the miasmata thus borne aloft far and wide over the county. It will be remembered too that last winter was particularly mild, there was almost no frost, and consequently little check to the vegetable decomposition which, rapid in warm weather, is generally suspended more or less during the colder months. Every circumstance, then, was favourable to the generation of the miasmata which we acknowledge as prime source of ague. One curious instance I met with of the direct and immediate influence of marsh effluvia.
It occurred in a gentleman connected with the oyster fishery, who, as often as he took a short cut across one particular marsh to the oyster beds, was seized with ague; but on making a circuit of a mile and a half out of the direct route, he as invariably escaped.

After no inconsiderable experience of intermittent fever, I must confess that my notions of its pathology are of the cloud. iest character. It is easy to comprehend the sequence of phenomena constituting the fit; but why, after this, a state of perfect health should supervene-why, in twenty-four, forty-eight, or seventy-two hours, there should be a recurrence of the attack-why this should be repeated at regular intervals, again and again-why a few doses of quinine should immediately break this chain of action-why a strong mental impression, as from the effect of so-called charms, should sometimes accom. plish an instantanecus cure, tending to the inference that agne is purely a nervous disorder-why, precisely at the end of a fortnight, or, as the popular idea is, at the change of the moon, if quinine be early discontinued, the fit should recur, not certainly invariably; but by no means infrequently. All these are matters to my mind involved in utter mystery, and I doubt whether our pathology of intermittent is very much in advance of what it was two hundred years ago. Even the learned Sydenham, who generally contrives to find some quaint reason for everything, and explains the most recondite phenomena of disease, completely to his own if not to our satisfaction, after sagely discoursing upon the turgescence, fermentation, and despumation of the blood, says, in allusion to the hidden fomes not pursuing its effervescence alike in all agues, "for sometimes it requires one day, sometimes three, before it comes to maturity and makes a new fit. I say, if any one should inquire about this matter, I would plainly confess I knew not, nor has any other that I know, sufficiently explicated this hidden work of nature."

He has an ingenious way of accounting for the long persist ence of ague in the system by regarding it as an ordinary fourteen or twenty-one day fever, eliminated, or carrying on its fermentation at intervals instead of continuously; for example, a quartan, he says, lasts six months, and allowing five hours and a half for every fit, you will find at the end of this period it has occupied exactly three hundred and thirty-six hours, or fourteen days, and so of the other forms. In our time, unless ague take its departure after two or three shakings, medical aid is had recourse to, so that when its natural termination might arrive it is difficult to say; but I fancy it would display a most uncertain and irregular character.

We do not find, at all events in this neighbourhood, that agues inflict any severe or permanent injury on the constitution, the enlarged spleen or ague-cake is not often detected; perhaps, not often enough looked for; for these disorders, from their frequency, come to get treated as matters of routine. At all events, save temporary internal congestions which, for aught $I$ know, may be the cause and not the effect of the paroxysm, we do not find evil consequences arise. Of course there are exceptions, but I can only call to mind one family in whom life was really imperilled by continued exposure to marsh miasmata. These people had removed from a more inland district to the borders of a marsh; they immediately became aguish, and, unless constantly under the counteracting influences of quinine, continued so. The once sturdy, ruddy children grew white, $N$ thin, flabby, and the youngest, an infant, died. The father, for- O merly robust, strong, and energetic, became pallid, feeble, and seldom fit for work. The mother fared worse still ; for, in addition to the failing powers which she shared in common with $N$ the rest of the family, she was frequently suffering from attacks 0 of what I then considered hepatitis, although subsequent ex- $\omega$ perience has led me to conceive that these might possibly have $O$ been only neuralgic seizures; still, accompanied as they were with a very rapid pulse and acute pain, one was fearful of not treating them in some degree antiphlogistically. At length $\varnothing$ the poor woman became gradually so utterly prostrate and? anæmiated-her pulse, a mere thread, always ranging over $120 \mathrm{~T}$ -her aspect that of one dying of hæmorrhage-that her hus- $\vec{c}$ band consented to have her lifted from her bed, put into a cart, $\mathbb{\mathbb { D }}$ and brought to Faversham; a removal of not more than two miles. He and his family followed. From that moment they $\mathbb{D}$ one and all began to improve, and to this day there is not a more hard-working, hearty, and robust family in the neighbours hood. This is, I say, an extreme case, such as I have met with once and only once. These people, it will be observed, wereo new comers; and new comers, 1 need scarcely tell you, always suffer most.

The acclimatised, or the natives, who are "to the manner? 
born," if they have ague do not appear to mind it. One old man I remember, who lived in a cottage on the marsh, and rejoiced in the ever green name of "May," continued in blossom for 101 years, notwithstanding he took his turns of ague with the rest.

In a disease concerning the pathology of which our notions are so indefinite and vague, it is no marvel that our treatment partakes of the empirical ; nevertheless, we may boast of having made some advance since the days of Sydenham, who says, "As to the cure of spring agues, I ever thought they were to be left to themselves without doing anything, because I never knew any one destroyed by them; and, on the contrary, that those who endeavoured to cure them made them only more obstinate and lasting."

We all now cure ague with the disulphate of quinine; but I am afraid none of us would give a very lucid explanation of its modus operandi, notwithstanding we look upon it almost as specific. Our intermittents here, with scarcely an exception, are all amenable to this remedy. We precede its administration by a calomel purge, repeating this, if there be hepatic con gestion, as often as may be required; push the quinine, not waiting for a clean tongue, to the extent of about twenty grain in the interval, and if our patient does not escape the next threatened attack, which, however, he frequently does, we may safely promise him immunity from any further seizure.

In obstinate cases, we combine the liquor potassæ arsenitis with the quinine. Arsenic alone requires time to produce its efiect on the system, and wo have seldom patience to wait when the more speedy remedy is at hand. In those cases which recur at the end of a fortnight, a few doses taken on the day or two preceding the expected ague-fit prove effectual in preventing it. The same mode of treatment is generally applicable to neuralgia in its multitudinous forms, although it must not be expected that these should yield so readily as simple intermittent fever; but quinine is still the remedy, in combination either with steel or arsenic. I have had little experience of the hydrochlorate of ammonia, so frequently prescribed by Dr. Watson, quinine proving all-sufficient for our needs; and I doubt not this is the experience of every one practising in localities where marsh miasmata are engendered. Change of air, provided it be sufficiently far from any source of malaria, is equally efficacious in arresting the disorder, but patients frequently have it again soon after their return; indeed, in those who are susceptible to the influences of marsh poison, nothing short of an entire removal will wholly do away with the liability to an occasional attack, a measure, however, unnecessary to be thought of so long as we have at command an antidote so powerful and efficacious as the disulphate of quinine.

\section{CASE OF HAMATURIA: CANCER OF BLADDER AND KIDNEYS: TUBERCLE IN LUNG.}

\section{By JoHN WV. Goodwis, MI.D., Physician to the Suffolk} General Hospial, Bury St. Edmund's.

T. J., aged 60 , by trade a plasterer, first consulted me in December 1856. His history was that until two months previously he had enjoyed good health, when he was seized with pain in the loins, and suffered some pain at the time of passing water over the region of the bladder; this pain extended down his thighs; he also experienced a difficulty in passing water for the first time in his life, and observed thet he passed one day about three tablespoonfuls of blood, after endeavouring to pass urine. Since this time he had occasionally passed quite clear urine, but it usually contained a good deal of blood. When I saw him, he looked sallow and cachectic, and his pain in the loins was very great and constant, and caused him to endeavour to pass urine very frequently. Pressure over the bladder did not cause pain. There were two enlarged inguina glands on the right side. After passing urine, he suffered pain at the end of the penis. He had never observed the stream of urine to be forked or stop suddenly. I directed him to be cupped every other day to a small amount of blood, and to apply the glasses for a considerable time each day, and to take ten grains of gallic acid with henbane and infusion of roses three times daily, and to keep in bed.

Upon examining his urine under the microscope, I found pus globules, red and white corpuscles of blood in large quantities, squamous epithelium, with large granular nuclei and nucleoli large round epithelium containing many resplendent granules, probably from the fundus of the bladder; and caudate and round cells with resplendent granules. I made a great many examinations during the time the patient was under my care, with the same results.

I tried lead and other styptic medicines without any marked effect, and he continued much in the same condition for three weeks, when I gave him the tincture of sesquichloride of iron in frequent small doses. He then continued about five days without passing blood, when he began to suffer from incontinence, and also from tenesmus and constant desire to evacuate the bowels. He was evidently getting weaker daily, and sank gradually, and died on the 17 th January, 1857.

A post mortem examination was made on 19 th January. The left lung, adherent at the apex to the costal pleura, contained several little masses of tubercular deposit, many in a state of suppuration, and several little cavities, of about the size of peas. The right lung was healthy. The heart was healthy. The liver contained one mass of cancerous matter, of about the size of $a$ walnut, in the anterior part of the larger lobe; this tumour was not encysted nor prominent from the surface, but was solid throughout, and somewhat denser than the hepatic tissue. The right kidney was slightly enlarged, and, with its cortical and intertubular portions, was white and condonsed. There was no mottling or granulation of the surface, the capsule readily peeling off. The left kidney was much larger than the right, with much cortical and interconical deposit. The bladder was much contracted; its walls were thickened to four or five times their natual size by the deposit of an uniform whitish material. From its mucous surface sprouted several small lobulations, having the same whitish appearance; there was no blood on their surface, but two small clots were found in the cavity of the bladder. The largest of these outgrowths was situated just behind the prostate, and was as large as a hazel.nut.

Such were the morbid appearances found; and my friend, Dr. Eade, was good enough to assist me in the microscopic examination of the morbid specimens.

The contents of the small pulmonary cavities were chiefly granular tubercle-corpuscles, masses of molecular matter, pus globules, and large oil globules, with one or two fragments of yellow elastic tissue. The juice scraped from the white tumour in the liver, showed myriads of very transparent cells of all conceivable forms; some contained one, others two or more nuclei, these nuclei containing nucleoli; some cells contained a large number of resplendent granules. The fluid scraped from the yellowish-white intertubular deposit in the right from the yellowish-white intertubular showed cells rather smaller than those in the liver; miny rous cor variously shaped; most of them with a large and very distinct nucleus, and all granulated them with a large and very distinct nucle or more nuclei. The fluid from the left kidney contained a great many cells, but of smaller size more like pus with bright central globules; here and there a caudate cell of a larger size was seen. Much free oil was present. The bladder-tumours were evidently medullary; and they were examined, with similar results as above.

ReMarks. Hæmaturia, as is well known, depends on a variety of causes, and in some cases it is often rather doubtful as to what the immediate cause may be, or where it is situated. Dr. Watson says in his Lectures that, as a general rule, most cases of hæmaturia, which appear to be doubtful, will prove to be renal. I think this is the case, but still $I$ think that we have such a powerful assistant in the microscope, that our difficulties of diagnosis are very much diminished. In this case, after one or two examinations of the urine, which was like porter and deposited very little sediment, I found such unusual appearances for urine, that $I$ at once suspected the nature of the case-such cells, so constant and of such complicated cha racter, could indicate, I imagined, nothing but cancer, and that of the bladder, and an opinion to that effect was ex pressed.

I have thought it desirable to publish this case, as it is, 1 think, interesting as regards the microscopic information which I obtained, and also that it furnishes an instance of an exception to the law which asserts that cancer and tubercle do not coexist in the same subject. There were no pulmonary sympcoexs during life, so that I never examined the lungs; but had I done so, no doubt there would have been auscultatory evidence of the tubercular disease, as there were small cavities, as well as softening tubercle. I should consider the disease in the bladder to be primary, and that in the kidneys and liver secondary deposit. 